Kansas State University Libraries

New Prairie Press

\title{
Transformational Learning in Botswana: How Culture Shapes the Process
}

Sharan B. Merriam

University of Georgia, USA

Gabo Ntseane

University of Botswana, Republic of Botswana

Follow this and additional works at: https://newprairiepress.org/aerc

Part of the Adult and Continuing Education Administration Commons

(c) (1) (9)

This work is licensed under a Creative Commons Attribution-Noncommercial 4.0 License

\section{Recommended Citation}

Merriam, Sharan B. and Ntseane, Gabo (2007). "Transformational Learning in Botswana: How Culture Shapes the Process," Adult Education Research Conference. https://newprairiepress.org/aerc/2007/ papers/70

This is brought to you for free and open access by the Conferences at New Prairie Press. It has been accepted for inclusion in Adult Education Research Conference by an authorized administrator of New Prairie Press. For more information, please contact cads@k-state.edu. 


\title{
Transformational Learning in Botswana: How Culture Shapes the Process
}

\author{
Sharan B. Merriam, University of Georgia, USA \\ Gabo Ntseane, University of Botswana, Republic of Botswana
}

\begin{abstract}
Transformational learning as presented by Jack Mezirow has been critiqued for its Western, rational/cognitive orientation. This study was conducted in the African nation of Botswana and examined how that culture shaped the process. The TL experiences of 10 adults were constructed in terms of spirituality and the metaphysical world, community responsibilities and relationships, and gender roles.
\end{abstract}

Transformational learning theory as presented by its chief architect, Jack Mezirow (2000), is about making sense of our experiences; it is a meaning-making activity. Meaningmaking related to everyday learning can be distinguished from meaning-making in transformative learning as follows: "normally, when we learn something, we attribute an old meaning to a new experience....In transformative learning, however, we reinterpret an old experience (or a new one) from a new set of expectations" (Mezirow, 1991, p. 11). This "new set of expectations" or meaning perspective is arrived at through critically reflecting upon the assumptions, biases, beliefs, and so on, that structure the old perspective. Mezirow has laid out a ten-stop process of transformative learning beginning with a disorienting dilemma that sets in motion a self-examination of one's underlying assumptions, followed by sharing these thoughts with others which leads to exploring new roles, relationships, and actions, a trying on of new roles, and finally, “a reintegration into one's life on the basis of conditions dictated by one's new perspective” (1991, p. 169).

Although much referenced in the adult learning literature, it wasn't until the early 1990s that empirical studies of transformational learning began to appear. Taylor's 2000 review of the research in this area was based on 46 studies using Mezirow's framework. Twenty additional studies were reviewed by Taylor in 2003. These studies together with six international conferences on transformative learning currently make transformational learning the most studied area of adult learning. From both the 2000 and 2003 reviews, Taylor concludes that research is generally supportive of “Mezirow's conception of transformative learning,... its stability over time, its relationship to expanding the self and pursuit of autonomy, and the applicability for informing classroom practice” (2003, ๆ 14). However, a number of questions remain to be addressed including the role of context, the nature of catalysts of transformative learning, the importance of emotion, spirituality and relationships in the process, and "the role of culture and transformation” ( $(14)$. It is this latter issue, the role of culture, that this study is designed to examine. We reasoned that studying transformational learning in a non-Western culture—Botswana—would provide a lens for examining how culture shapes the process.

\section{Transformative Learning and Cultural Context}

As might be expected, a number of writers have pointed out the Western bias in Mezirow's theory. Rational thinking is a particularly Western concept, a product of the Descartes' mind-body split and the Enlightenment's emphasis on science and rationality. "Selfreflection and critical thinking may be reputed to be universal 'goods,' but we need to be aware 
of their cultural specificity and power” (Hanson, 1996, p. 105). Research on perspective transformation has found that it is not a totally rational, cognitive process. Taylor $(1997$, p. 48) summarizes as follows: "Multiple studies refer to the significance of intuition (Brooks), affective learning (Clark, Scott, Sveinunggaard), extrarational influences (Vogelsang), and the guiding force of feelings (Hunter, Taylor).” Taylor (2000) recommends that more research be conducted which explores the affective and relational qualities of transformational learning.

The role of context--cultural, historical, and social--is another area where research is needed. Mezirow does acknowledge that context plays a role in transformational learning: "The process of self-empowerment, acquiring greater control of one's life as a liberated learner, is of course, always limited by social, historical, and cultural conditions." He goes on to say that "our life histories and language are bound up with those of others. It is within the context of these relationships, governed by existing and changing cultural paradigms, that we become the persons we are” (2000, p. 27).

However, he does not elaborate on how this happens. With regard to cultural considerations in transformative learning, no studies were found. Taylor (2000) concurs, commenting that "much more research is still needed with a primary focus on the role of culture and transformative learning” (pp. 311-312).

\section{The Cultural Context of Botswana}

Botswana is a country in Southern Africa sharing borders with Zimbabwe, Zambia, Angola, Namibia and South Africa. The population is approximately 1.6 million with $25 \%$ of the population living in its two urban centers of Gaborone and Francistown. Colonized for a time by the British, Botswana has been independent since 1966. While there are a number of ethnic groups and 22 recognized languages, certain cultural values appear to be common to most Batswana (the term used to refer to the people of Botswana). First, Batswana are collectivistic; identity is determined by the collectivity or group to which one belongs, not by individual characteristics. The Southern African cultures embrace spirituality, connectedness and Úbuntu'(South Africa) and 'botho'(Botswana). These concepts encompass ideas of respect for human life, mutual help, generosity, cooperation, respect for older people, and harmony and preservation of the sacred. Commitment to the family includes an obligation to the living and the dead and those yet to be born. Their lives are embedded in a complex web of ties to family, village, country, and/or social group, where mutual and reciprocal obligations are clearly understood and acted upon.

The literature makes a number of observations about traditional African value systems and learning. Such values embrace essentially a collective, rather than an individual concept of responsibility. Some Southern African values include: Spirituality - participation that is influenced by the metaphysical world, resulting in a sense of obligation to the community and encapsulated in spiritual obligation to one's ancestors and a physical obligation to take care of the extended family; Communal - emphasis on awareness of others, promoting cooperation; and Political - interpreted as duties that serve the interest of the nation or community before oneself. It was anticipated that these cultural values would be manifested in some way in the transformational learning experiences of adults in Botswana. The question for us was in what ways this cultural context shapes the nature of transformational learning.

\section{Method}

To understand how culture shapes the nature of transformative learning in Botswana, a qualitative research design was employed. The sample consists of 12 Batswana adults in the 
capital city of Gabarone who volunteered to be interviewed after acknowledging that they had had an experience which had profoundly changed their view of themselves and/or their perspectives on the world. As most urban Batswana speak English as well as their native language, interviews were conducted in English. Interview transcripts were analyzed using the constant comparative method of data analysis (Strauss \& Corbin, 1990). Of the 12 participants 8 are female and 4 are male. Participants ranged in age from early 20s to late 60s. Level of education extended from no formal schooling to university graduate.

\section{Findings}

In our analysis of their experiences dealing with a life event that triggered the transformational learning process we focused on how the cultural context of Botswana shaped how participants processed and interpreted the event. Not surprisingly, the "disorienting dilemma" that precipitated the process consisted of life events common to people everywheredeath of a child, illness, car accident, betrayal, and so on. Even Dira's disorienting dilemma of being "called" to be a sangoma, or spiritual healer, can be compared in other settings to being called to a particular vocation. The process that a life event sets in motion was also found to be loosely isomorphic with the process Mezirow proposes; that is, participants examined underlying assumptions, tried out new roles, actions, and so on, eventually integrating their new perspective into their lives. In only a couple of cases did we see the "rational discourse" phase of the process, however. In this phase of Mezirow's model, discourse is "dialogue devoted to searching for a common understanding and assessment of the justification of an interpretation or belief" (Mezirow, 2000, pp. 10-11). Most of our participants worked through the process internally over time.

In answer to our overarching research question of how cultural context shaped the process of transformational learning, we found three culturally-specific factors. They are spirituality and the metaphysical world, community responsibilities and relationships, and gender roles. Each of these is presented below with supporting data from our interviews.

\section{Spirituality and The Metaphysical World}

What we are identifying as spirituality/the metaphysical world permeated our participants' interpretation of the process and outcome of transformational learning. Some of the events that triggered the TL process were seen as being caused by forces beyond the natural world and how most of our participants responded to the event were in reference to ancestor spirits or the ultimate authority (God). This spiritual system runs parallel to and is independent of a person's particular religious affiliation.

Bashi, a 45 year old businessman and President of the African Catholic Sacred Heart Society presents a good example of how this spiritual system defined his transformational learning experience. Bashi's 12-year-old daughter was hit by a car and killed. Prior to her death Bashi and his brother had had a falling out and his brother sought revenge by having a traditional doctor use his powers to "silence" Bashi. Bashi tells us:

Now traditionally, if I am strong enough, and somebody is trying to provoke me with the traditional medicines, under normal circumstances they will not come to me, if I am strong enough. They will rather maybe show up in somebody, maybe my relative, maybe my child. So when we were still in this misunderstanding, it happened that my first born daughter was knocked down by a vehicle.

He explains that this death had to happen to bring about reconciliation between the brothers, to strengthen his and his wife's faith, and to bring peace to the family. In her death, his 
daughter Phatsimo, has become a "saint" who watches over them. She is an "angel” who "mediates" for them.

In Mama-B's processing of her husband's suicide, she not only examines her assumption that there has to be a reason why he did it, she also struggles with what she calls "African things" as the cause: “African things because where he was working” a co-worker went into her husband's office and called in witchdoctors.

Perhaps the most dramatic example of the metaphysical world defining the transformational learning process is exemplified in the case of Dira, a 35-year-old businessman. Dira becomes very sick and neither modern nor traditional doctors can heal him. He visits a spiritual healer who said Dira "was too powerful for their power to heal. In fact one of them said, 'you are not really sick; the Badimo want to use you to heal other people.'” He resists, saying he is happy as a successful businessman. However, he again became deathly ill and this time the "the spirits did whisper in my ear that 'You have to be one of us on earth, otherwise we take you. We will give you only six months to decide. When you do decide to serve with us go to spiritual healer so-and-so who has instructions on how to train you." Dira says that if he didn't listen to "the command of the spirits" his family "might be cursed to the grave." He gave up his business, has begun work with a healer and his health problem has disappeared.

\section{Community Responsibilities and Relationships}

In contrast to a focus on the individual, many non-Western cultures emphasize the collective; the individual has little if any identity separate from the larger community, whether the community is the family, the tribe, the local community, or other extended networks. It was not surprising then, to find that transformational learning was shaped by community responsibilities and relationships. That is, processing the disorienting dilemma was in relation to family or the community at large; at times these factors intersected to shape the transformational learning experience.

Community responsibilities and relationships shape how Mosedinyane has made meaning of her HIV/AIDS diagnosis. She came to realize she needed "to declare my status in my community and the nation at large.” She has been making presentations in schools and at national conferences. In her words,

After spending time beating myself about having been rough with God's temple, I have learnt that what individuals go through (good or bad) is for society's continuity. Yes! I am going to die, but I am happy that I have given something valuable to my people. This deadly ailment has ensured that I become a teaching and learning tool for my people. What can be better than that? My cultural belief that "go swa motho go sala mothor" or "one individual dies but another remains" is true. I am ready for death, but have wiped tears of pain and shame because of having been a responsible member of those I am leaving behind.

\section{Gender Roles}

In Botswana, gender roles are strictly defined. We found that several of the women in our study processed their transformational learning in terms of traditional women's roles. Lesedi, like many other young women in Botswana, sought escape from poverty by becoming the girlfriend of an older man. Lesedi naively assumes she has a future with him but when she finds out he is married and has children she feels betrayed. She ends the relationship but not before becoming infected with HIV, which further adds to her betrayal. She is still working through this betrayal and feels that she is "trying to go back to God because maybe I was lost, maybe he took 
me that way to learn something." She feels she has become stronger, that "nothing can crush me.” Her view of men has changed--they are not interested in love, just sex, and she doesn't trust them.

For a couple of our participants, the transformational learning had to do with the questioning and final rejection of the gender-specific roles in marriage. In Botswana, when a woman marries she joins her husband's family, in some cases actually moving in with the family. She is expected to take care of the husband's parents, raise children, and support the husband even if he is abusive, alcoholic or has girlfriends. If something happens to the man in Botswana culture, it is assumed to be the wife's fault. For example, Mama-B, whose husband committed suicide, told us that her son-in-law went to the police charging her with murder. Abuse is also seen as the woman's fault. She cannot leave him and her family will not take her in. Grandma-T, now in her 60s, told us she first ran away to South Africa from an arranged marriage when her husband became abusive because she had not conceived a child. Years later her second husband also became abusive but by the time it got really bad she had three children. She continued to stay in the marriage until she had a dream in which a voice said, "'This man will kill you.' That was the turning point.” Grandma-T now feels an abuser never changes and that "You don't need more than three years to decide to leave. That is what I will tell every woman....So I will say marriage is a gift from God and if it is not your gift don't waste time. Move on.”

\section{Discussion}

While we know the cultural context in which any learning takes place is crucial to understanding that learning, to date we were unable to find any research which explicitly analyzed how culture shapes a transformational learning experience. Transformational learning studies have focused on delineating the process, the role of rational discourse, and the nature of the changed perspective. Furthermore, these studies have been conducted in the West where individuality, autonomy, and rationality are accepted cultural values. By locating this study in a non-Western culture, we were able to see how culture shapes meaning-making. As we noted earlier, the disorienting dilemmas that triggered the transformational learning process were life events common to people everywhere. Further, stages in the meaning-making process were found to be loosely congruent with the steps Mezirow (1991) proposes. Where we found the culturally relevant material was in the challenging of certain culturally-based assumptions (such as the wife being husband's property) and in the construction of the new perspective (such as how the community benefits from a person's actions).

From witchdoctors casting spells, to ancestor spirits being appeased, to accounting for one's actions before an ultimate force, the role of the metaphysical world permeated the transformational learning process of our participants. A second cultural factor that shaped our participants' meaning-making was a sense of community responsibility and relationships. In a communal culture such as Botswana's, people do not strive for an identity as an individual. Rather, their identity is through their community, tribe, and social group. The third cultural factor that we saw shaping the experiences of our participants is gender roles, and in particular women's roles. While certainly gender, a socially-constructed phenomenon, shapes people's experiences in every culture, it is the particular construction of women's gender in Botswana that was both challenged and operational in the learning process of women in our study.

While we have illustrated each of these three factors with data from our participants, in reality, these three cultural factors are often interrelated. For example, because Webu is the 
eldest daughter, society expects her to take the lead in caring for her ill mother. Webu in fact becomes the mother figure for the rest of the family. So, gender roles and family responsibilities are intertwined as is the spiritual. She must assume this role to ensure her mother's peaceful death so that the ancestral spirits will be good to those still living.

That cultural values shape which assumptions are examined and what new perspectives and subsequent behaviors are engaged in calls into question some aspects of Mezirow's theory. For example, the outcome of transformational learning in Mezirow's theory is increased autonomy and individual empowerment. Such a claim needs to be examined in light of a particular cultural context. The transformed perspective of some of our Batswana participants led them to be more aware of their interdependent positionality, rather than being more discriminating and autonomous. This study has made visible how cultural context shapes transformational learning; but it is only a beginning. We would like to see more studies that focus on this question, even studies in the West where the assumed cultural values that seem to frame the whole theory of perspective transformation can be brought to light.

\section{References}

Hanson, A. (1996). The search for a separate theory of adult learning: Does anyone really need andragogy? In R. Edwards, A. Hanson, and P. Raggatt (Eds.), Boundaries of adult learning. New York: Routledge.

Mezirow, J. (1991). Transformative dimensions of adult learning. San Francisco: Jossey-Bass.

Mezirow, J. \& Associates (2000). Learning as transformation. San Francisco: Jossey-Bass.

Taylor, E. W. (1997). Building upon the theoretical debate: A critical review of the empirical studies of Mezirow's transformative learning theory. AEQ, 48, 32-57.

Taylor, E. W. (2000). Analyzing research on transformative learning theory. In Mezirow, J. \& Associates, Learning as transformation (pp. 285-328). San Francisco: Jossey-Bass.

Taylor, E. W. (2003). Looking back five years: A critical review of transformative learning theory. Proceedings of the Fifth International Conference on Transformative Learning. New York: Teachers College, Columbia University. 